\title{
Anal cancer precursor lesions in HIV-positive and HIV-negative patients seen at a tertiary health institution in Brazil ${ }^{1}$
}

\author{
Lesões precursoras do câncer anal em pacientes HIV-positivos e HIV-negativos atendidos numa \\ instituição de saúde terciária no Brasil
}

\author{
Ivan Tramujas da Costa e Silva ${ }^{\mathrm{I}}$, José de Ribamar Araújo ${ }^{\mathrm{II}}$, Rosilene Viana de Andrade ${ }^{\mathrm{II}}$, Celso Rômulo Barbosa Cabral ${ }^{\mathrm{III}}$, \\ Felicidad Santos Gimenez ${ }^{\mathrm{IV}}$, Adriana Gonçalves Daumas Pinheiro Guimarães ${ }^{\mathrm{V}}$, Ticiane Costa Martins ${ }^{\mathrm{VI}}$, Lucília Rocha Lopes ${ }^{\mathrm{VI}}$, \\ Luiz Carlos de Lima Ferreira ${ }^{\mathrm{VII}}$
}

\begin{abstract}
${ }^{1}$ Research performed at the Outpatient Clinic of Coloproctology and the Division of Pathology of the Tropical Medicine Foundation of Amazonas, Manaus-AM, Brazil. Part of a PhD thesis in Tropical and Infectious Diseases of the Post-Graduation Program of the Tropical Medicine Foundation of Amazonas, University of the State of Amazonas (UEA). Tutor: Luiz Carlos de Lima Ferreira.

${ }^{\mathrm{I}} \mathrm{MD}$, Fellow PhD degree, Post-Graduation Program of Tropical Medicine Foundation of Amazonas, UEA. Assistant Professor of Surgery, Federal University of Amazonas (UFAM), Manaus-AM, Brazil. Contribution: main author; study concept and design; acquisition of data; analysis and interpretation of data; drafting of the manuscript; critical revision of the manuscript for important intellectual content; obtained funding; study supervision; technical support; composition of the manuscript in the English language.

${ }^{I I}$ MD, Master, Division of Pathology, Tropical Medicine Foundation of Amazonas. Assistant Professor of Pathology, UEA, Manaus-AM, Brazil. Participated in study concept and design; acquisition of data; critical revision of the manuscript for important intellectual content; technical support.

${ }^{\text {III }} \mathrm{PhD}$, Associate Professor, Department of Statistics, Exact Sciences Institute, UFAM, Manaus-AM, Brazil. Participated in study concept and design; analysis and interpretation of data; statistical analysis; critical revision of the manuscript for important intellectual content.

${ }^{\mathrm{IV}} \mathrm{MD}$, Master, Volunteer Faculty, Department of Surgery, UFAM, Manaus-AM, Brazil. Participated in study concept and design; acquisition of data; critical revision of the manuscript for important intellectual content; technical support.

${ }^{\mathrm{v}} \mathrm{MD}$, Fellow PhD degree, Post-Graduation Program of Tropical Medicine Foundation of Amazonas, UEA. Assistant Professor of Surgery, UFAM, Manaus-AM, Brazil. Participated in study concept and design; acquisition of data; critical revision of the manuscript for important intellectual content; technical support.

${ }^{\mathrm{VI}} \mathrm{MD}$, Resident, Getúlio Vargas University Hospital, UFAM, Manaus-AM, Brazil. Acquisition of data; critical revision of the manuscript for important intellectual content; technical support.

${ }^{\mathrm{VII}} \mathrm{MD}, \mathrm{PhD}$, Department of Research and Division of Pathology, Tropical Medicine Foundation of Amazonas. Associate Professor of Pathology, UFAM, Manaus-AM, Brazil. Tutor. Study concept and design; critical revision of the manuscript for important intellectual content; obtained funding; study supervision; technical support.
\end{abstract}

\begin{abstract}
Purpose: To investigate the prevalence of anal squamous intraepithelial lesions (ASIL) or anal cancer in patients attended at the Tropical Medicine Foundation of Amazonas. Methods: 344 patients consecutively attended at the institution, in 2007/2008, were distributed in the following strata according to presence/abscense of at risk conditions for anal cancer: Group 1 - HIV-positive men-who-have-sex-with-men (101); Group 2 - HIV-positive females (49); Group 3 - patients without any at risk condition for anal cancer (53); Group 4 - HIV-positive heterosexual men (38); Group 5 - HIV-negative patients, without anoreceptive sexual habits, but with other at risk conditions for anal cancer (45); Group 6 - HIV-negative men-who-have-sex-with-men (26); and Group 7 - HIVnegative anoreceptive females (32). The histopathological results of biopsies guided by high-resolution anoscopy were analyzed by frequentist and bayesian statistics in order to calculate the point-prevalence of ASIL/cancer and observe any eventual preponderance of one group over the other. Results: The point-prevalence of ASIL for all the patients studied was 93/344 (27\%), the difference between HIV-positive and negative patients being statistically significant $(38.3 \%$ versus $13.5 \%$; p $<0.0001)$. The prevalence of ASIL for each one of the groups studied was: Group $1=49.5 \%$, Group $2=28.6 \%$, Group $3=3.8 \%$, Group $4=21.1 \%$, Group $5=11.1 \%$, Group $6=30.8 \%$ and Group $7=18.8 \%$. Standard residual analysis demonstrated that ASIL was significantly prevalent in patients of Group 1 and high-grade ASIL in patients of Group 2. The odds for ASIL of Group 1 was significantly higher in comparison to Groups 2, 3, 4, 5 and 7 ( $p<0.03$ ). The odds for ASIL of Groups 2, 4 and 6 were significantly higher in comparison to Group $3(p<0.03)$. Conclusions: In the patients studied, ASIL (low and/or high-grade) tended to be significantly more prevalent in HIV-positive patients. Nonetheless, HIV-negative anoreceptive patients also presented great probability to have anal cancer precursor lesions, mainly those of the male gender.
\end{abstract}

Key words: Anal Canal. Anus Neoplasms. Epidemiology. HIV. 


\section{RESUMO}

Objetivo: Investigar a prevalência de lesões intraepiteliais escamosas anais (ASIL) ou câncer anal em pacientes atendidos na Fundação de Medicina Tropical do Amazonas. Métodos: 344 pacientes consecutivamente atendidos na instituição, em 2007/2008, foram distribuídos nos seguintes estratos conforme a presença/ausência de fatores de risco para o câncer anal: Grupo 1 - homens-que-fazem-sexo-comhomens HIV-positivos (101); Grupo 2 - mulheres HIV-positivas (49); Grupo 3 - pacientes sem condição de risco para o câncer anal (53); Grupo 4 - homens heterossexuais HIV-positivos (38); Grupo 5 - pacientes HIV-negativos, sem hábitos sexuais anorreceptivos, mas com outras condições de risco para o câncer anal (45); Grupo 6 - homens-que-fazem-sexo-com-homens HIV-negativos (26); e Grupo 7 - mulheres HIV-negativas, com hábitos sexuais anorreceptivos (32). Os resultados histopatológicos das biópsias anais dirigidas pela colposcopia anal foram analisados por meio de estatística frequentista e bayesiana para a determinação da prevalência-ponto de ASIL/câncer e verificar eventual preponderância estatística de um grupo sobre o outro. Resultados: A prevalência-ponto de ASIL para todos os pacientes estudados foi de 93/344 (27\%), sendo significativa a diferença entre HIV-positivos e negativos (38,3\% versus $13,5 \% ; p<0,0001)$. A prevalência de ASIL para cada um dos grupos estudados foi: Grupo $1=49,5 \%$, Grupo $2=28,6 \%$, Grupo $3=$ $3,8 \%$, Grupo $4=21,1 \%$, Grupo $5=11,1 \%$, Grupo $6=30,8 \%$ e Grupo $7=18,8 \%$. A análise de resíduos demonstrou prevalência significante de ASIL para o Grupo 1 e de ASIL de alto-grau para o Grupo 2. A razão-de-chances do Grupo 1 para ASIL foi significantemente maior em comparação com os Grupos 2, 3, 4, 5 e $7(p<0,03)$. A razão-de-chances para ASIL dos Grupos 2,4 e 6 foi significantemente maior em comparação com o Grupo $3(p<0.03)$. Conclusões: Nos pacientes estudados, ASIL (baixo e/ou alto-grau) foi significantemente mais prevalente em pacientes HIV-positivos. Entretanto, pacientes HIV-negativos anorreceptivos também apresentaram grande probabilidade de possuir as lesões, especialmente os do gênero masculino.

Descritores: Canal Anal. Neoplasias do Ânus. Epidemiologia. HIV.

\section{Introduction}

Anal cancer, although rare in the general population, has shown an increase in incidence in recent decades in some sections of the population considered at greater risk of developing the disease ${ }^{1}$.

The disease is associated with continued anal human papillomavirus (HPV) infection. About $75 \%$ of the sexually active population will develop HPV anogenital infection throughout life, although most of the affected individuals will not present clinical signs of the illness ${ }^{2}$. When present, these signs (mainly anal intraepithelial neoplasia, or AIN) are similar to those found in association with cervical cancer, a malignancy with which anal cancer shares many characteristics ${ }^{3}$.

Following the classification of cervical intraepithelial neoplasia, anal cancer precursor lesions, alike, have been conventionally defined as AIN 1, AIN 2 and AIN 3. In accordance with what is experienced with cervical intraepithelial neoplasia, to minimize considerable inter and intra-observer interpretative variability, the 2001 Bethesda Classification System of cellular atypia is used so that AIN 1 is defined as LSIL (low-grade squamous intraepithelial lesion) and AIN 2 and 3 are unified in a sole category, HSIL (high-grade squamous intraepithelial lesion) ${ }^{4}$.

Patients with HSIL lesions are at an increased risk to develop anal cancer ${ }^{5}$. Nevertheless, depending on the genotype of the infecting HPV, in the presence of infection with multiple HPV types and under immunodepressive conditions, lesions considered to be LSIL at admittance can evolve to HSIL. This is the case for individuals infected with acquired immunodeficiency virus (HIV-positive) and especially for HIV-positive men-who- have-sex-with-men (MSM) ${ }^{6}$. However, even among women, the incidence of anal cancer is 7 times greater in HIV-positive individuals in contrast to HIV-negative with other at risk conditions for the malignancy ${ }^{2}$.

Strict follow-up policies directed at patients considered to be at risk to develop anal cancer have been implemented in some institutions based on data that indicate a historical increase in the incidence of the malignancy in these population groups ${ }^{7}$. Therapeutic management of lesions at a higher risk to evolve to malignant degeneration is the objective of these policies in an attempt to reduce the incidence of anal neoplasia ${ }^{8}$.

The Tropical Medicine Foundation of Amazonas (FMT-AM) is a public health service of the state of Amazonas, Brazil, specialized in the treatment of infectious diseases. The majority of HIV infected individuals of the state are referred to FMT-AM for diagnosis, follow up and treatment. From January 2007, HIV-positive patients followed up in the institution, as well as other HIV-negative patients presenting colorectal complaints, were referred to its Coloproctology Outpatient Clinic. Until then, there was no consolidated data on the magnitude of the frequency of anal cancer precursor lesions among patients managed only at FMT-AM.

This work was, therefore, designed to evaluate the frequency of anal squamous intraepithelial lesions (ASIL) and anal cancer in patients who were examined at the institution in order to gather evidence to corroborate the need to implement a follow-up and treatment routine program directed at patients at risk of developing anal malignancy. 


\section{Methods}

\section{Ethics and patients}

This cross-sectional observational study was approved by the Ethics in Research Committee of FMT-AM (CEP/FMT-AM n $\left.{ }^{\circ} 1768 / 2006\right)$. The data relative to the patients herein included were collected from those seeking medical evaluation at FMT-AM and referred to the institution's Coloproctology Outpatient Clinic for consultation from January 2007 to December 2008.

The population studied included consecutively attended HIV-positive and HIV-negative individuals, from both genders, with and without risk factors for the development of anal cancer who had never before been submitted to coloproctological examination or sampling at FMT-AM.

All the individuals presenting one the following criteria were excluded: age below 18 years, developmental disabilities, native Brazilian Indians, those who did not complete any stage of specimen collection, those with missing or unsatisfactory specimens, and those missing crucial data for statistical analysis.

All the patients who signed the Informed Consent forms were interviewed and responded to a questionnaire directed at their epidemiological characteristics and anal cancer risk conditions.

Out of the 399 patients examined in the study period, after applying inclusion and exclusion criteria, 344 were screened for analysis. These patients were further stratified in the following groups according to the presence or absence of anal cancer risk conditions: Group 1 = HIV-positive MSM (101 patients); Group 2 = HIV-positive females (49 patients); Group 3 = individuals of both genders without anal cancer risk factors or behaviors (53 patients); Group 4 = HIV-positive heterosexual males (38 patients); Group $5=$ HIV-negative individuals of both genders without anoreceptive sexual habits, but that reported at least one among the other inquired anal cancer risk factors or behaviors (current tobacco smoking, injection drug addiction, sexually transmitted diseases, solid organ transplantation, and history of anogenital cancer or its precursor lesions) (45 patients); Group $6=$ HIV-negative MSM (26 patients); and Group 7 = HIV-negative females with anoreceptive sexual habits (32 patients).

\section{Biopsy proceedings}

All the patients were submitted to high-resolution anoscopy with biopsies after topical application of a $3 \%$ acetic acid solution for 2 minutes as described elsewhere ${ }^{9}$, but with the following modifications: at least two biopsies were made in the anal canal of each subject. Patients without acetowhitening at high-resolution anoscopy were submitted to biopsies within the anal transitional zone at standard positions ( 4 and 7 o'clock, considering the anterior anal commissure as 12 o'clock). Patients with anal canal acetowhitened lesions had all of them biopsied and an additional biopsy was performed in a non-acetowhitened anal transitional zone area.
The formalin-fixed biopsy specimens were delivered to the Department of Pathology of FMT-AM for processing and evaluation. Hematoxilin-eosin-stained slides prepared from $4 \mu \mathrm{m}$-thick sections of the paraffin blocks containing the anal specimens were diagnosed by three pathologists. Only consensual results were considered. The projected possible histopathological results were: negative-for-ASIL (LSIL or HSIL) or cancer, including benign inflammatory alterations, condyloma acuminatum, LSIL, HSIL, epidermoid carcinoma in situ, adenocarcinoma in situ, invasive epidermoid carcinoma, and invasive adenocarcinoma.

Anal condyloma, LSIL and HSIL were diagnosed according to well established morphological parameters ${ }^{10}$.

\section{Statistical analysis}

Statistical analyses of the observed data were performed with R statistical software ${ }^{11}$ for the entire population sample, considering ethnic and educational differences, for HIV-positive and HIV-negative patients, and for the population sample strata that considered the presence or absence of anal cancer risk factors or behaviors.

Descriptive summaries of epidemiological characteristics were evaluated. The population sample characteristics were tested against the observed histopathological results using frequentist and Bayesian - via R package LearnBayes ${ }^{12}$ - statistical methods for analysis of contingency tables, the Monte Carlo test ${ }^{13}$, analysis of Standard Residuals and Correspondence Analysis.

The odds for association with ASIL were calculated for each combination of two strata of patients. Statistical significance was inferred whenever the $p$-value of conventional statistical tests was found below 5\%, when Bayesian posterior probabilities favored some given hypothesis and when absolute values of standard residuals were above 1.96

For the statistical analysis, LSIL results encompassed anal condyloma, and only one result was attributed per patient: that with the highest grade of severity in the Negative-for$\mathrm{ASIL} \rightarrow \mathrm{ASIL} \rightarrow$ Cancer sequence.

\section{Results}

Due to missing data in respect to some non-crucial study variables, the sample size of some epidemiological analyses varied.

Regarding the ethnic breakdown, the larger number of brown skinned patients reflects the regional ethnic composition of the Amazonian population. In terms of educational level, patients with less than a higher educational level were significantly more numerous $(p<0.0001)$. The distribution of ASIL-positive and ASIL-negative histopathological results in relation to the ethnic groups and to the educational level showed no differences either by frequentist or by Bayesian statistical analyses (Bayes factor $=0.001963119$ for ethnic characteristics and 0.01647418 for educational level). The prevalence of ASIL in all the patients analyzed showed a significant difference between HIV-positive and HIV-negative individuals (Table 1). 
TABLE 1 - Frequencies of histopathological results of anal biopsies by ethnic breakdown, level of education and hiv status

\begin{tabular}{|c|c|c|c|c|c|c|c|c|}
\hline & \multicolumn{7}{|c|}{$\mathrm{HP}$} & \multirow[b]{2}{*}{$p$-value* } \\
\hline & ASIL $\oplus$ & $\%$ & $95 \% \mathrm{Cl}$ & ASIL $\theta$ & $\%$ & $95 \% \mathrm{Cl}$ & TOTAL & \\
\hline Ethnic Category & - & & & - & & & - & \\
\hline White Brazilian & 21 & 27.63 & $17.99-39.09$ & 55 & 72.37 & $60.91-92.01$ & 76 & \\
\hline Pardo Brazilian & 66 & 27.16 & $21.67-33.22$ & 177 & 72.84 & 66.78-78.33 & 243 & \\
\hline Afro-Brazilian & 3 & 17.65 & $3.80-43.43$ & 14 & 82.35 & $56.57-96.20$ & 17 & \\
\hline Asian Brazilian & 0 & 0.00 & $0.00-77.64$ & 2 & 1.00 & $22.36-1.00$ & 2 & \\
\hline TOTAL & 90 & 26.63 & $21.99-31.68$ & 248 & 73.37 & $68.32-78.01$ & 338 & 0.6818 \\
\hline Level of Education & - & & & - & & & - & \\
\hline Primary & 26 & 21.14 & $14.30-29.42$ & 97 & 78.86 & $70.58-85.70$ & 123 & \\
\hline Secondary & 48 & 29.45 & $22.58-37.08$ & 115 & 70.55 & $62.92-77.42$ & 163 & \\
\hline Higher & 15 & 31.91 & $19.09-47.12$ & 32 & 68.09 & $52.88-80.91$ & 47 & \\
\hline Illiterate & 1 & 33.33 & $0.84-90.57$ & 2 & 66.67 & $9.43-99.16$ & 3 & \\
\hline TOTAL & 90 & 26.79 & $22.12-31.86$ & 246 & 73.21 & 68.14-77.88 & 336 & 0.3497 \\
\hline HIV & - & & & - & & & - & \\
\hline Positive & 72 & 38.30 & $31.32-45.65$ & 116 & 61.70 & $54.35-68.68$ & 188 & \\
\hline Negative & 21 & 13.46 & $8.53-19.84$ & 135 & 86.54 & $80.16-91.47$ & 156 & \\
\hline TOTAL & 93 & 27.03 & $22.41-32.06$ & 251 & 72.97 & 67.94-77.59 & 344 & 0.0001 \\
\hline
\end{tabular}

$\mathrm{HP}=$ histopathological result; $\operatorname{ASIL}(+)$ = positive for anal squamous intraepithelial lesion; ASIL(-) = negative for ASIL; $95 \% \mathrm{CI}=95 \%$ Confidence Interval; $* X^{2}$ Pearson's Test

The mean age of all the screened patients was 39 years. MSM tended to be younger than females (33 years versus 40 years) and patients without risks for anal cancer older than all others groups (46 years).
Table 2 shows the distribution of frequencies of histopathological results of the anal canal biopsies performed in all the patients studied relative to their sample strata.

TABLE 2 - Frequencies of anal canal histopathological diagnoses according to population sample strata studied

\begin{tabular}{|c|c|c|c|c|c|c|c|c|c|c|}
\hline \multirow[b]{2}{*}{ Group } & \multicolumn{10}{|c|}{ Histopathological Result } \\
\hline & LSIL & $\%$ & $95 \% \mathrm{Cl}$ & HSIL & $\%$ & $95 \% \mathrm{Cl}$ & NEG & $\%$ & $95 \% \mathrm{Cl}$ & Total \\
\hline (1) & 29 & 28.71 & $20.15-38.57$ & 21 & 20.79 & $13.36-30.01$ & 51 & 50.50 & $40.36-60.60$ & 101 \\
\hline (2) & 3 & 6.12 & $1.28-16.87$ & 11 & 22.45 & $11.77-36.62$ & 35 & 71.43 & $56.74-83.42$ & 49 \\
\hline (3) & 1 & 1.89 & $0.05-10.07$ & 1 & 1.89 & $0.05-10.07$ & 51 & 96.23 & $87.02-99.54$ & 53 \\
\hline (4) & 5 & 13.16 & $4.41-28.09$ & 3 & 7.89 & $1.66-21.38$ & 30 & 78.95 & $62.68-90.45$ & 38 \\
\hline (5) & 3 & 6.67 & $1.40-18.27$ & 2 & 4.44 & $0.54-15.15$ & 40 & 88.89 & $75.95-96.29$ & 45 \\
\hline (6) & 5 & 19.23 & $6.55-39.35$ & 3 & 11.54 & $2.45-30.15$ & 18 & 69.23 & $48.21-85.67$ & 26 \\
\hline (7) & 6 & 18.75 & $7.21-36.44$ & 0 & 0.00 & $0.00-8.94$ & 26 & 81.25 & $63.56-92.79$ & 32 \\
\hline Total & 52 & 15.12 & $11.50-19.35$ & 41 & 11.92 & 8.69-15.82 & 251 & 72.97 & 67.94-77.59 & 344 \\
\hline
\end{tabular}

(1) HIV-positive men who have sex with men (MSM); (2) HIV-positive females; (3) individuals of both genres without anal cancer risk factors; (4) HIV-positive heterosexual males; (5) HIV-negative individuals of both genres without anoreceptive sexual habits, but with other anal cancer risk factors; (6) HIV-negative MSM; (7) HIV-negative females with anoreceptive sexual habits; LSIL = low grade squamous intraepithelial lesion; HSIL $=$ high grade squamous intraepithelial lesion; $\mathrm{NEG}=$ biopsy negative for anal squamous intraepithelial lesion. $95 \% \mathrm{CI}=95 \%$ Confidence Interval; G-Test $($ Williams $)=64.4682(\mathrm{P}<0.0001)$ 
As some of the cells of Table 2 contain less than 5 subjects, a feature that could compromise the validity of the conventional statistical analysis of the data disposed in the table, which pointed to a $p$-value below 0.0001, a Monte Carlo test was initially applied to the same data. The approximated $p$-value obtained was 0.0004998 , indicating that the null hypothesis of independence should indeed be rejected, a reflex of statistical significance. A Bayesian analysis of the data was also undertaken for the same purpose and the value of the Bayes factor was $480,615.50$, indicating a very strong evidence against the existence of independence, again indicating statistical significance.

As all the statistical methods employed led to the same results, it could be stated that the strata of the population sample studied showed very different histopathological findings when compared to each other.

The mosaic plot of Figure 1 is a pictorial representation of the proportions of frequencies showed in Table 2 relative to each Group of patients. The width of each bar is representative of the size of the respective Group, while the height of each one of the three segments that form a bar represents the proportional distribution of frequencies of histopathological results (LSIL, HSIL and NEG) regarding every individual Group of patients.

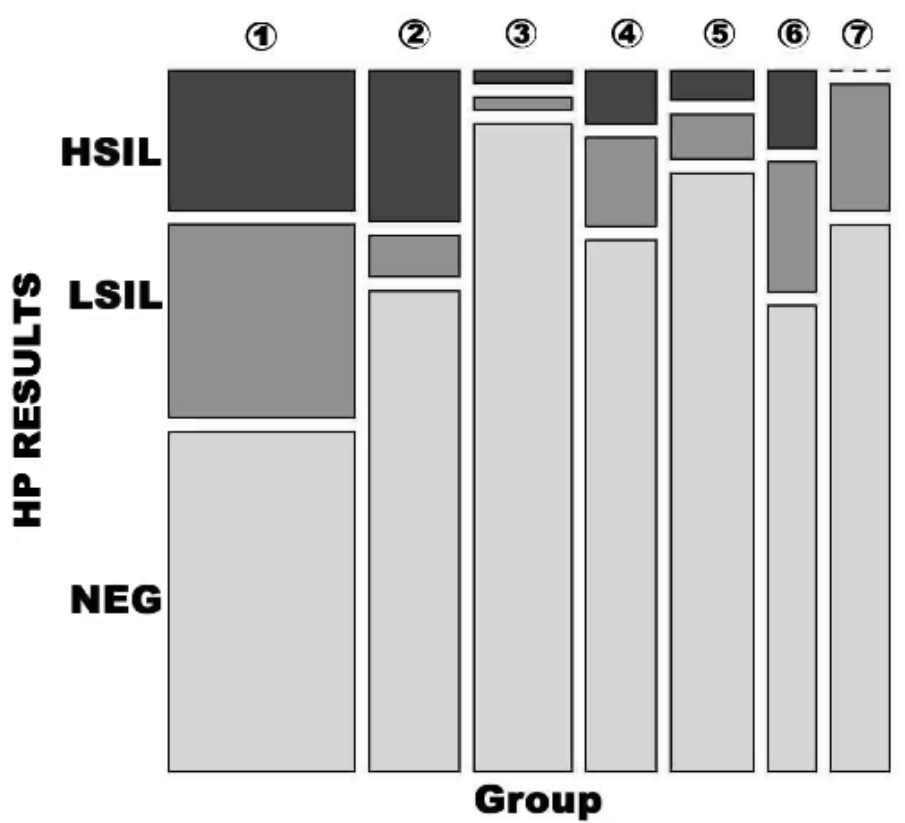

FIGURE 1 - Distribution of proportional frequencies of histopathological results of anal biopsies

$\mathrm{HP}=$ histopathological; (1) HIV(+) men-who-have-sex-with-men (MSM); (2) HIV $(+)$ females; (3) individuals of both genders without anal cancer risk factors; (4) HIV(+) heterosexual males; (5) HIV(-) individuals of both genders without anoreceptive sexual habits, but with other anal cancer risk factors; (6) HIV(-) MSM; (7) HIV(-) females with anoreceptive sexual habits; LSIL = low-grade squamous intraepithelial lesion; HSIL = high-grade squamous intraepithelial lesion; $\mathrm{NEG}=$ biopsy negative for anal squamous intraepithelial lesion.
It can be visually perceived in Figure 1 that patients of Groups 1 and 6 showed evident association with positive results for ASIL (LSIL and HSIL), that patients of Group 2 showed evident association with HSIL, and that patients of Group 7 showed evident association with LSIL. As to results NEG, the most evident association is that presented by patients of Group 3. Despite being friendly, though, this is an entirely intuitive assessment.

An evaluation of the behavior of the dependence between histopathological results versus nature of sample strata was then undertaken by the analysis of standard residuals (Table 3 ).

TABLE 3 - Analysis of standard residuals of the frequencies of histopathological results relative to the population sample strata studied

\begin{tabular}{cccc}
\hline & \multicolumn{3}{c}{ Histopathological results } \\
\cline { 2 - 4 } Group & HSIL & LSIL & NEG \\
\hline (1) & 2.58 & 3.51 & -2.64 \\
(2) & 2.14 & -1.62 & -0.13 \\
(3) & -2.16 & -2.48 & 1.98 \\
(4) & -0.72 & -0.31 & 0.43 \\
(5) & -1.45 & -1.46 & 1.25 \\
(6) & -0.06 & 0.54 & -0.22 \\
(7) & -1.95 & 0.53 & 0.55 \\
\hline
\end{tabular}

(1) HIV-positive men-who-have-sex-with-men (MSM); (2) HIVpositive females; (3) individuals of both genres without anal cancer risk factors; (4) HIV-positive heterosexual males; (5) HIV-negative individuals of both genres without anoreceptive sexual habits, but with other anal cancer risk factors; (6) HIV-negative MSM; (7) HIVnegative females with anoreceptive sexual habits; HSIL = high-grade squamous intraepithelial lesion; LSIL $=$ low-grade squamous intraepithelial lesion; NEG = biopsy negative for anal squamous intraepithelial lesion.

The highest positive residuals were given by the combinations: Group $1+$ ASIL (either LSIL or HSIL), Group 2 + HSIL and Group 3 + Negative-for-ASIL. The most pronounced negative residuals were observed with: Group $3+$ ASIL, Group 1 + Negative-for-ASIL and Group 7 + HSIL.

Finally, concentrating the values of rows LSIL and HSIL, from Table 2, in a single row called ASIL, the odds ratios for ASIL of Group 1 were estimated against the histopathological results of each one of the other groups. The associated confidence intervals were also obtained as well as a test for the hypothesis of equal odds (Table 4). 
TABLE 4 - Comparative Odds ratios of group (1) of presenting anal squamous intraepithelial lesions

\begin{tabular}{cccc}
\hline Group & OR & $95 \% \mathrm{Cl}$ & $\mathrm{p}$-value \\
\hline (2) & 2.45 & $1.20-5.22$ & 0.0164 \\
(3) & 25.00 & $7.22-158.07$ & $<0.0001$ \\
(4) & 3.68 & $1.60-9.31$ & 0.0034 \\
(5) & 7.84 & $3.10-24.18$ & $<0.0001$ \\
(6) & 2.21 & $0.90-5.80$ & 0.0918 \\
(7) & 4.25 & $1.70-12.21$ & 0.0035 \\
\hline
\end{tabular}

(1) HIV-positive men-who-have-sex-with-men (MSM); (2) HIVpositive females; (3) individuals of both genders without anal cancer risk conditions; (4) HIV-positive heterosexual males; (5) HIV-negative individuals of both genders without anoreceptive sexual habits, but with other anal cancer risk conditions; (6) HIVnegative MSM; (7) HIV-negative females with anoreceptive sexual habits; $\mathrm{OR}=$ odds ratio; $95 \% \mathrm{CI}=95 \%$ Confidence Interval

The greatest Odds ratio was observed between Groups 1 and 3. The hypothesis of equality between the odds for ASIL of Groups 1 and 6 could not be rejected, considering the observed $95 \%$ Confidence Interval and the corresponding $p$-value $(p=$ 0.0918). Inequality was observed in all other comparisons. The odds ratios formed between the remaining combinations of two groups were also tested. All of them were non-significant, except for those obtained between Groups 2 and $3(10.20 ; 95 \%$ Confidence Interval $=2.18-47.71 ; p=0.0031), 6$ and $3(11.33$; $95 \%$ Confidence Interval $=2.20-58.43 ; p=0.0037)$, and 4 and 3 $(6.80 ; 95 \%$ Confidence Interval $=1.35-34.15 ; p=0.0199)$.

\section{Discussion}

This work is based on an analysis of frequencies of histopathological diagnoses observed in anal canal biopsies performed in HIV-positive and HIV-negative patients by attending Coloproctologists at FMT-AM. All patients underwent biopsy proceedings, including those who had no obvious acetowhite lesions during high-resolution anoscopy. This is a differential aspect of this study, considering that if only individuals with positive anal cytology and anoscopy were included, patients in whom these diagnostic tests were false-negative would have been excluded. Two biopsies were performed in each acetowhite negative patient in order to minimize the chance of false negative anoscopy interpretations. On the other hand, there were cases of diffuse anal transitional zone acetowhitening either due to wart rings or to nonspecific staining. Multiple biopsies were performed for all these cases.

Statistical analysis of data gathered for this study is distinctive in the aspect that it was conducted contrasting conventional tests (frequentist, such as Chi-square and G tests) with non-conventional (mainly Bayesian analysis and analysis of standard residuals), in order to validate the final conclusions.

The Bayesian method is based on the computation of the Bayes factor, which is the ratio of probabilities observed after data collection of two considered hypotheses (presence of independence versus lack of independence). It measures the evidence against the existence of independence. A result greater than 1.00 favors lack of independence (statistical significance). Otherwise, the hypothesis of independence is to be accepted.

The analysis of standard residuals is a mensuration of the degree of deviation of the measurements away from the hypothesis of independence. Each residual is calculated as (observed - expected)/expected ${ }^{2}$, in which observed represents the cell value and expected is the expected value of the cell considering the null hypothesis was true. Roughly, it is assumed that residuals with absolute values above 1.96 represent cells with more individuals than expected for independence (statistical significance).

The non-conventional statistics employed in this study corroborated and reinforced the results obtained by frequentist statistics.

Abramowitz et al. ${ }^{14}$ reported $108 \mathrm{HPV}$-related lesions in 473 HIV-positive patients of both genders with or without anoreceptive sexual habits $(22.8 \%)$. The prevalence of ASIL (condyloma included) was $36.5 \%$ in HIV-positive MSM, $14.6 \%$ in HIV-positive heterosexual males and $11.3 \%$ in HIV-positive females, but only $47.2 \%$ of these lesions were located solely in the anal canal. Comparatively, in FMT-AM's survey of exclusively intra-anal HPV-induced lesions, the prevalence of ASIL among HIV-positive patients was $38.30 \%$ (49.50\% in MSM, $28.57 \%$ in females and $21.05 \%$ in heterosexual males).

The initially managed group of HIV-positive individuals at FMT-AM showed a prevalence of ASIL above $60 \%$, but most of them had AIDS or HIV infection for many years. Durable HIV infection seems to be accompanied by a higher risk for ASIL because the frequency of precursor lesions of anal cancer in HIV-positive patients has shown a tendency to increase since the advent of highly active antiretroviral therapy ${ }^{2,5,6}$.

As the coloproctological examination consolidated as a routine for the initial evaluation of HIV-positive individuals at FMT-AM, the frequency of those with a less-than-a-yeardiagnosed retrovirus increased, so that it ultimately comprised $54.6 \%$ of all HIV-positive patients herein included. Although patients with prolonged HIV infection may be at greater risk to present $\mathrm{ASIL}^{8}$, it remains to be shown, in studies analyzing the prevalence of ASIL in HIV-positive patients, that it is important to consider the length of time of HIV infection ${ }^{14}$.

HIV-positive MSM are known to be the population group most likely to develop anal cancer, and are followed by HIV-negative MSM and by HIV-positive females, ${ }^{2,15}$. In HIVpositive MSM, the prevalence of ASIL is also high, and was reported to be $81 \%$ in 357 patients studied at the University of California at San Francisco ${ }^{16}$. In fact, anoreceptive habits increase the likelihood that male patients present ASIL compared with anoreceptive females since MSM tend to have anoreceptive sexual activity more frequently than women and also are prone to have more anal-introducer sexual partners, which makes them more likely to have anal HPV infection ${ }^{17}$. Furthermore, HIV infection confers MSM a relative risk 5.7 times greater to have ASIL than HIV-negative $\mathrm{MSM}^{15}$. 
Prevalence of ASIL in men investigated at FMT-AM was significantly higher among HIV-positive than in HIV-negative $(p=0.0003)$ irrespective of the presence of other risk factors for anal cancer. Among HIV-positive men, it was higher in MSM than in heterosexual $(p=0.0045)$. Nevertheless, ASIL was not statistically more prevalent in HIV-positive men (MSM or heterosexual) compared to HIV-negative MSM ( $p=0.1363$ and $p=0.3094$, respectively), meaning that, in men, "HIV-infection" and "receptive anal intercourse" factors appeared both to be influential in association with ASIL.

Prevalence of cytological or histological ASIL in HIV-positive females was estimated to be $14.5 \%$ in a multicentric study recently conducted at five academic centers in the U.S ${ }^{18}$. Although comparatively smaller than the one reported for HIV-negative MSM in the EXPLORE study (20\%), which was based on cytological results ${ }^{19}$, both prevalences are considerably higher than that described by Holly et al. ${ }^{17}(8 \%)$ in HIV-negative females with other risk factors for anal cancer in a study also based on cytological results.

In this study, HIV-positive females showed a frequency of HSIL significantly higher than anoreceptive HIV-negative females $(p=0.0064)$, while the latter had a frequency of LSIL higher than the former, but without statistical significance ( $p=0.1139$ ). Even considering that $75 \%$ of the HIV-positive females studied practiced anoreceptive sex and that the other risk factors for anal cancer were unevenly distributed between the two groups, it could be reasoned that, in the females studied, the condition of being HIV-positive was linked to the elevated association with HSIL and that the practice of anoreceptive sex predisposed HIV-negative females to LSIL association. Indeed, in Hessol et al. ${ }^{18}$ study of a cohort of HIV-positive and HIV-negative US women, all at risk for anal cancer development, those who reported anal intercourse were 3.8 times more likely to have anal LSIL than women with no history of anoreceptive sex, while HIV-positive women were 3.1 times more likely to have anal HSIL than HIV-negative women.

Despite that it was not possible to rigorously and independently indicate the exact factors mostly associated with the presence of ASIL in each population strata, since some confounding factors could not be dissociated in the strata (e.g.: HIV-positive MSM, HIV-positive females, HIV-positive heterosexual males, HIV-negative MSM and HIV-negative anoreceptive females could or could not have other risk factors for anal cancer, such as current tobacco smoking) it may be inferred from the comparative analysis of the proportions of the frequencies of the histopathological diagnoses observed among the groups, that conditions "anal intercourse" and "HIV infection" were those associated with more positive results for LSIL and/or HSIL. The absence of risk factors for anal cancer (presented by Group 3 of patients) was, conversely, the feature most significantly associated with negative results (and also with lower rates of positive results) for ASIL.

One can argue that groups 3 and 5 should not be compared to the remaining groups since they were composed of patients from both genders, while the others were not. Nevertheless, there was no statistical difference between genders in the distribution of ASIL within groups 3 and 5.
Although the population sample strata observed in this study were unevenly sized, including some with few individuals, the combined evaluation of the data done by frequentist and alternative statistical methods suggests, with a high degree of confidence, that HIV-positive MSM were significantly more associated with ASIL results than all other groups, except for HIV-negative MSM; that HIV-positive females were significantly more associated with HSIL results than all other groups, except for HIV-positive MSM; and that patients from Group 3 were significantly more associated with Negative-for-ASIL results than all other groups, except for Group 5.

One can argue that groups 3 and 5 should not be compared to the remaining groups since they were composed of patients from both genders, while the others were not. Nevertheless, there was no statistical difference between genders in the distribution of ASIL within groups 3 and 5 .

\section{Conclusions}

In the patients studied, anal squamous intraepithelial lesions (low and/or high-grade) tended to be significantly more prevalent in HIV-positive patients. Nonetheless, HIV-negative anoreceptive patients also presented great probability to have anal cancer precursor lesions, mainly those of the male gender.

\section{References}

1. Daling JR, Weiss NS, Hislop TG, Maden C, Coates RJ, Sherman KJ, Ashley RL, Beagrie M, Ryan JA, Corey L. Sexual practices, sexually transmitted diseases, and the incidence of anal cancer. N Engl J Med. 1987;317:973-7

2. Bratcher J, Palefsky J. Anogenital human papillomavirus infection and associated neoplasia in HIV-positive men and women. The PRN Notebook. 2008;13:1-8. Available from: <http://www.prn.org/images/pdfs/ 502 bratcher_palefsky.pdf $>$

3. Melbye M, Sprogel P. Aetiological parallel between anal cancer and cervical cancer. Lancet. 1991;338:657-9.

4. Biggar RJ, Melbye M. Marital status in relation to Kaposi's sarcoma, non-Hodgkin's lymphoma, and anal cancer in the pre-AIDS era. J Acquir Immune Defic Syndr Hum Retrovirol 1996;11:178-82.

5. Chin-Hong PV, Palefsky JM. Natural history and clinical management of anal human papillomavirus disease in men and women infected with human immunodeficiency virus. Clin Infect Dis. 2002;35:1127-34.

6. Palefsky JM. Anal cancer prevention in HIV-positive men and women. Curr Opin Oncol. 2009;21:433-8.

7. Goldie SJ, Kuntz KM, Weinstein MC, Freedberg KA, Welton ML, Palefsky JM. The clinical effectiveness and cost-effectiveness of screening for anal squamous intraepithelial lesions in homosexual and bisexual HIV-positive men. JAMA. 1999;281:1822-9.

8. Palefsky JM, Cranston RD. Anal intraepithelial neoplasia: Diagnosis, screening and treatment. In: Dezube BJ and Ross ME (Ed). UpToDate, Waltham, MA, 2009. Available from: <http://www.uptodate.com/online/ content/topic.do?topicKey=tumorhiv/2317>.

9. Costa e Silva IT, Ferreira LCD, Gimenez FS, Guimaraes RAG, Fujimoto LB, Cabral CRB, Mozzer RV, Atala LDS. High-resolution anoscopy in the diagnosis of anal cancer precursor lesions in renal graft recipients. Ann Surg Oncol. 2008;15:1470-5.

10. Longacre TA, Kong CS, Welton ML. Diagnostic problems in anal pathology. Adv Anat Pathol. 2008;15:263-78. 
11. R DEVELOPMENT CORE TEAM. R: A language and environment for statistical computing. Vienna: R Foundation for Statistical Computing, 2008. Available from: <http://www.R-project.org >

12. Albert J. LearnBayes: Functions for Learning Bayesian Inference. Vienna: R Foundation for Statistical Computing, 2008. Available from: $<$ http://cran.r-project.org/web/packages/LearnBayes/LearnBayes.pdf $>$ 13. Hope ACA. A simplified Monte Carlo significance test procedure. J Roy Statist Soc B. 1968;30:582-98.

14. Abramowitz L, Benabderrahmane D, Ravaud P, Walker F, Rioux C, Jestin C, Bouvet E, Soule JC, Leport C, Duval X. Anal squamous intraepithelial lesions and condyloma in HIV-infected heterosexual men, homosexual men and women: prevalence and associated factors. AIDS. 2007;21:1457-65.

15. Palefsky JM, Holly EA, Ralston ML, Arthur SP, Jay N, Berry JM, DaCosta MM, Botts R, Darragh TM. Anal squamous intraepithelial lesions in HIV-positive and HIV-negative homosexual and bisexual men: prevalence and risk factors. J Acquir Immune Defic Syndr Hum Retrovirol. 1998;17:320-6.

16. Palefsky JM, Holly EA, Efirdc JT, Da Costa M, Jay N, Berry JM, Darragh TM. Anal intraepithelial neoplasia in the highly active antiretroviral therapy era among HIV-positive men who have sex with men. AIDS. 2005;19:1407-14.
17. Holly EA, Ralston ML, Darragh TM, Greenblatt RM, Jay N, Palefsky JM. Prevalence and risk factors for anal squamous intraepithelial lesions in women. J Natl Cancer Inst. 2001;93:843-9.

18. Hessol NA, Holly EA, Efird JT, Minkoff H, Schowalter K, Darragh TM, Burk RD, Strickler HD, Greenblatt RM, Palefsky JM. Anal intraepithelial neoplasia in a multisite study of HIV-infected and high-risk HIV-uninfected women. AIDS. 2009;23:59-70.

19. Chin-Hong PV, Vittinghoff E, Cranston RD, Browne L, Buchbinder S, Colfax G, Da CM, Darragh T, Benet DJ, Judson F, Koblin B, Mayer $\mathrm{KH}$, Palefsky JM. Age-related prevalence of anal cancer precursors in homosexual men: the EXPLORE study. J Natl Cancer Inst. 2005;97:896-905.

\section{Acknowledgments}

The authors are grateful to Pathology Laboratory Technicians Sandra Caranhas, Andreza Fernandes and to Administrative Technician Agustinho Monteiro for their expert technical assistance.

\section{Correspondence:}

Ivan Tramujas da Costa e Silva

R. Afonso Pena, 1053

69020-160 Manaus - AM Brasil

itramujas@ufam.edu.br

Received: July 06, 2010

Review: September 14, 2010

Accepted: October 19, 2010 